\title{
SAÚDE DO IDOSO: PERCEPÇÕES DOS PROFISSIONAIS DE ENFERMAGEM PERANTE O MANEJO CLÍNICO DA DOR
}

\author{
HEALTH OF THE ELDERLY: PERCEPTIONS OF NURSING PROFESSIONALS \\ BEFORE THE CLINICAL MANAGEMENT OF PAIN
}

\author{
Jéssica Maria Moccelin, Arlete Eli Kunz da Costa, Luís Felipe Pissaia, Sabrina Monteiro
}

Universidade do Vale do Taquari - UNIVATES

\begin{abstract}
With the increase in life expectancy, the human being is vulnerable to the natural, dynamic and irreversible process of aging and the picture of pain can exacerbate this situation. Therefore, the pain sensation needs to be diagnosed, measured, evaluated and properly treated by professionals. This study aims to identify the perception of the nursing team regarding the evaluation and measurement of pain intensity in the elderly. This is an exploratory-descriptive study, with a qualitative approach, carried out with four nurses and six nursing technicians working in the Pronto Care of a medium-sized hospital in a city of Rio Grande do Sul. It was verified that despite the majority of professionals consider it important to evaluate and measure pain, all of them perform this process in a non-systematized way and have incipient knowledge about the new technologies used to manage pain sensation in the elderly. In summary, it is necessary to reorganize the nursing care offered to the elderly with pain seeking hospital care, pointing to pain management as a fundamental point for the humanization of care and quality of care.
\end{abstract}

Key words: Old man. Pain evaluation. Pain measurement. Nursing care.
Resumo

Com o aumento da expectativa de vida, o ser humano fica vulnerável ao processo natural, dinâmico e irreversível do envelhecimento $e$ o quadro da dor pode agravar essa situação. Sendo assim, a sensação álgica necessita ser diagnosticada, mensurada, avaliada $e$ devidamente tratada. Dessa forma, estudo objetiva identificar a percepção da equipe de enfermagem quanto a avaliação e mensuração da intensidade da dor em idosos. Trata-se de uma pesquisa exploratório-descritiva, com abordagem qualitativa, realizada com quatro enfermeiros e seis técnicos em enfermagem que trabalham no Pronto Atendimento de um hospital de médio porte de um município do Rio Grande do Sul, Brasil. Verificou-se que apesar da maioria dos profissionais considerar importante avaliar e mensurar a dor, todos eles realizam este processo de forma não sistematizada e possuem saberes incipientes quanto as novas tecnologias utilizadas para o manejo da sensação álgica em idosos. Em suma, destaca-se sobre a necessidade de reorganizar a assistência de enfermagem oferecida aos idosos com dor que procuram atendimento hospitalar, apontando o manejo desta como ponto fundamental para a humanização da assistência e qualidade do atendimento.

Palavras chave: Idoso. Avaliação da dor. Medição da dor. Assistência de enfermagem. 
Introdução
O envelhecimento é um assunto ainda pouco estudado devido à complexidade com que ocorre, pois se trata de um processo individual e subjetivo inerente à trajetória evolutiva humana, e que na contemporaneidade merece destaque pelo aumento significativo no número de pessoas idosas. ${ }^{1} \mathrm{O}$ indivíduo idoso é aquele por regra detentor de idade igual ou superior há 60 anos, sendo ainda passível de disfunções próprias do envelhecer biológico, que ocorre através do aparecimento de sinais e sintomas próprios da fase, incluindo-se a dor. ${ }^{2}$

A dor foi definida pela Associação Internacional para o Estudo da Dor (IASP) como uma experiência sensorial e emocional desagradável, sendo associada a lesões reais ou potenciais. ${ }^{1}$ Desta forma, Ciena e colaboradores ${ }^{1}$ afirmam que em 1996, foi introduzida pela American Pain Society, como quinto sinal vital. Reiterando o pressuposto, Queiróz et al. ${ }^{2}$ preconizam que o sinal deve ser sempre avaliado e registrado com mesmo rigor e seriedade que a Pressão Arterial, Frequência Cardíaca, Frequência Respiratória e Temperatura Corporal.

Em consonância, Silva e Ribeiro Filho ${ }^{3}$, ratificam que a dor é, essencialmente, uma experiência subjetiva e pessoal, e que desta forma, cada indivíduo reage a ela de maneira diferente, considerando-se também a sua intensidade. Nesse contexto, Sallum, Garcia e Sanches ${ }^{4}$ apontam que o sentimento da dor é influenciado por fatores complexos relacionados aos campos afetivos, biológicos, psicológicos, sociais e culturais do ser humano e, que estes elementos merecem atenção dos profissionais, pois o seu desconhecimento dificulta a qualidade e resolutividade da assistência.

Giro e Paúl ${ }^{5}$ perfazem que com o aumento da expectativa de vida, o ser humano fica vulnerável ao processo natural, dinâmico, progressivo e irreversível do envelhecimento. Os mesmos autores salientam que com a deterioração do organismo maduro aumenta o índice de doenças incapacitantes, crônicas e degenerativas. Neste âmbito, Rios e colaboradores ${ }^{6}$ afirmam que em casos de saúde fragilizada, o quadro da dor pode agravar esta situação, refletindo negativamente no autocuidado e, consequentemente, à perda progressiva da qualidade de vida do indivíduo.

Ademais, é notório que a dor nos idosos representa um importante problema de saúde pública, e conforme Andrade, Pereira e Sousa ${ }^{7}$ necessita ser diagnosticado, mensurado, avaliado e devidamente tratado pelos profissionais de saúde, reduzindo a morbidade e aumentando a qualidade de vida. Em alusão, Monfrim e colaboradores $^{8}$ dissertam que com o intuito de subsidiar as ações dos profissionais e permitir quantificar e qualificar a evolução da dor de cada indivíduo, foram elaborados instrumentos que utilizam parâmetros comportamentais e fisiológicos, dentre esses instrumentos, cita-se as escalas para avaliação da dor.

Partindo desse pressuposto, a presente pesquisa pautou-se pelos seguintes problemas de investigação: Como a equipe de enfermagem reconhece a dor enquanto sinal vital? A avaliação da dor é utilizada no atendimento aos idosos? Quais metodologias de mensuração da intensidade da dor são utilizadas e conhecidas pelos profissionais? Quais são os impactos suscitados pela utilização da avaliação da dor no atendimento aos idosos? Para responder a estes questionamentos, estabeleceu-se como objetivo identificar a percepção da equipe de enfermagem quanto a avaliação e mensuração da intensidade da dor em idosos.

\section{Limiar histórico do reconhecimento da dor enquanto sinal vital}

Ao longo dos anos o ser humano vem procurando compreender as múltiplas faces da dor, com o intuito de cessá-la. Diante dessas acepções, Araujo e Romero ${ }^{9}$ apontam que a sua compreensão foi sendo empregada de várias formas. Em 320 a.C., Aristóteles considerou a dor como sendo uma "antítese ao prazer" atentando para uma sensação desconfortável, entretanto, ao longo da história, essa ideia foi sendo difundida e atribuída não somente aos componentes sensitivos, mas também afetivos. Cabe destacar que esta relação entre dor física e sofrimento psíquico vem sendo estudada até a contemporaneidade.

Contudo, as descobertas mais importantes sobre a dor, ocorreram após a II Guerra Mundial, decorrentes da expansão do conhecimento sobre anatomia e fisiologia e a utilização de métodos científicos para averiguar os significados dela ${ }^{9}$. Nesta mesma perspectiva, Nascimento e Silva ${ }^{10}$ dissertam que apenas na década de 70 a definição de dor foi instituída, sendo conceituada pela IASP como uma experiência sensorial e emocional desagradável, associada às lesões reais ou potenciais.

Assim sendo, infere-se que na experiência dolorosa, aspectos sensitivos, emocionais e culturais estão associados e devem ser igualmente analisados. Nesse sentido, Thé ${ }^{11}$ reporta a ideia que a dor é uma experiência 
subjetiva e que a sua percepção pode oscilar entre as pessoas, em termos de qualidade, intensidade, localização e fatores emocionais envolvidos. Ademais, Cunha e Mayrink ${ }^{12}$, destacam que sua presença interfere consideravelmente na autonomia do indivíduo, limitando a capacidade funcional e, consequentemente, prejudicando a qualidade de vida.

A dor passou a ser classificada pela Join Comission on Accreditation of Healthcare Organization - JCAHO (Comissão Conjunta de Acreditação das Organizações de Saúde), no ano de 2000, como quinto sinal vital, devendo ser avaliada e registrada impreterivelmente com os demais sinais vitais ${ }^{13}$. Portanto, a avaliação e os cuidados dispensados no controle da dor devem ser realizados de forma sistemática por profissionais capacitados e que utilizem de uma metodologia assistencial que favoreça a sua identificação, consequentemente, produzindo um cuidado integral e humanizado ${ }^{14}$.

\section{Instrumentos utilizados para mensuração da dor em idosos}

A dor é retratada como um fenômeno subjetivo, sendo difícil qualificá-la ou quantificála devido a diversidade de fatores biológicos, emocionais e sociais que the são intrínsecas. Todavia, Leão e Chaves $^{15}$ reforçam que é fundamental que ela seja avaliada e mensurada, devido ao papel que desempenha tanto no diagnóstico, como na terapêutica, favorecendo na recuperação do paciente. Nesse sentido, Ciena e outros ${ }^{1}$ salientam que o alívio da sensação álgica é uma necessidade humana básica, e transpassa os direitos fundamentados pelo indivíduo, tratando-se de uma questão clínica e ética envolvendo todos os profissionais.

Em relação a mensuração da dor, esta refere-se a graduação de um número ou valor que pode ser indicado por meio de um instrumento unidimensional, mensurando somente a intensidade dela. Já a avaliação da dor, conforme Fortunato e colaboradores ${ }^{14}$ é um processo mais amplo e envolve a obtenção de informações relacionadas à data de início, à localização, à intensidade, à duração e às qualidades sensoriais e afetivas da dor. A articulação entre os dois processos, segundo Sousa ${ }^{16}$ auxilia na sintetização das informações coletadas e capturadas, subsidiando o profissional na elaboração do diagnóstico, prognóstico e planejamento de estratégias para o controle e manejo da sensação álgica.

A equipe de enfermagem pode utilizar diversas escalas para mensurar a intensidade da dor do indivíduo, entretanto, os profissionais devem estar atentos para a indicação de cada escala. Nascimento e Silva ${ }^{10}$ afirmam que cada indivíduo possui a sua particularidade, devendo ser considerado a idade, habilidades de comunicação, prejuízo cognitivo e físico dele. Nestas circunstâncias, Martinez, Grassi e Marques $^{17}$, destacam que instrumentos de avaliação da dor mais complexos podem dificultar a aplicação pelos auxiliares e técnicos de enfermagem, sendo melhores conduzidos pelos enfermeiros.

Conforme Sousa et al. ${ }^{18}$, as mensurações da dor podem ser divididas em três categorias, englobando o ser humano na sua integralidade. $A$ primeira consiste na verificação das respostas físicas do indivíduo, relacionadas com observações e relatos verbais; a segunda engloba escalas que quantificam a experiência dolorosa em uma só dimensão (unidimensionais); e a última consiste na avaliação multidimensional da dor. Neste contexto, Fortunato e outros ${ }^{14}$ apontam que os instrumentos unidimensionais são vantajosos por sua rápida e fácil aplicabilidade. Entre as escalas unidimensionais mais utilizadas, destacam-se a Escala de Categoria Verbal/Numérica, a Escala Analógica Visual e a Escala de Faces de dor.

No que concerne aos instrumentos multidimensionais, estes possuem a vantagem de conseguir avaliar a dor em toda a sua complexidade, como por exemplo, intensidade, localização e qualidades afetivas e sensoriais dela. Dentre as escalas mais utilizadas dessa categoria podemos citar o Questionário McGill de Avaliação da Dor, a Escala de Descritores Diferenciais e a Teoria da Detecção do Sinal ${ }^{15}$.

Andrade, Pereira e Sousa ${ }^{7}$ destacam que, em idosos, a capacidade de expressar a dor pode ficar comprometida, devido às alterações das habilidades cognitivas, das funções sensórioperceptivas e motoras, que interferem na comunicação e, consequentemente, na avaliação e mensuração da dor. Assim, Fontes e Jaques ${ }^{19}$ reforçam que os profissionais devem estar atentos às manifestações comportamentais, como caretas, posturas encurvadas, punhos cerrados, tremor, mudanças de modulação da voz e manifestações de gemido e choro.

Partindo desse pressuposto, é perceptível a necessidade da obtenção de conhecimento e realização de treinamentos pela equipe de enfermagem com relação à avaliação e mensuração da dor em idosos ${ }^{9}$. Nessa perspectiva, Heinen e colaboradores ${ }^{20}$ ressaltam que não basta somente o aprendizado empírico 
do cotidiano de quem lida com estes indivíduos para planejar a assistência de enfermagem, tornando-se imprescindível a utilização de instrumentos de avaliação da dor para direcionar a atuação destes profissionais.

\section{Metodologia}

Este estudo tem um caráter exploratório e descritivo, com abordagem qualitativa. Os dados foram coletados em um hospital de médio porte do interior do Rio Grande do Sul, Brasil, tendo como população alvo a equipe de enfermagem que atua no Pronto Atendimento (PA) da referida instituição.

A amostra foi composta por 10 profissionais de enfermagem, sendo seis de nível técnico e quatro de superior, que atuam nesta unidade nos turnos manhã, tarde e noite $A$ e noite $B$. Foi disponibilizado pela instituição um espaço individual, no qual foram gravados os diálogos, a fim de garantir a privacidade e sigilo das informações. Como critérios de inclusão determinamos que o entrevistado deveria ser profissional de enfermagem, de nível técnico ou superior que atuasse no PA com tempo de trabalho na instituição de um ano ou mais, e que concordasse em participar voluntariamente da pesquisa, assinando o Termo de Consentimento Livre e Esclarecido (TCLE).

Para a coleta dos dados foi utilizado um questionário semiestruturado, constituído por quatro questões de caracterização da amostra e cinco questões de livre expressão, ou seja, descritivas, relacionadas ao reconhecimento, avaliação e mensuração da dor. O questionário foi desenvolvido pelo próprio grupo de pesquisa. A análise dos dados foi classificada em modalidades de pontos focais compatíveis, conforme a Análise de Conteúdo de Bardin ${ }^{21}$, sendo que esta técnica é permeada pelas seguintes etapas: Pré-análise; Exploração do material; Tratamento dos resultados obtidos e interpretação.

É oportuno mencionar que, a fim de garantir o anonimato dos participantes do estudo, utilizou-se de codinomes para identificalos, sendo utilizadas as letras "PE" maiúsculas, seguidas de números arábicos aleatórios. Salienta-se que a presente pesquisa atendeu às determinações preconizadas pela Resolução $\mathrm{n}$ 은 466/2012 do Conselho Nacional de Saúde (CNS) para pesquisas envolvendo seres humanos, sendo sua realização permitida pela coordenação geral de enfermagem da instituição. O projeto foi aprovado pelo Comitê de Ética em Pesquisa (COEP) da Universidade do Vale do Taquari
UNIVATES por meio do parecer no 2.172.207.

\section{Resultados e Discussões}

O estudo teve como participantes quatro enfermeiros e seis técnicos em enfermagem que atuam no PA da instituição hospitalar, os quais apresentam idade mínima de 21 e máxima de 52 anos. Quanto ao gênero sete mulheres e três homens. Esses resultados reforçam uma característica retratada na literatura, no que diz respeito à enfermagem enquanto uma profissão predominantemente feminina, sendo composta por $84,6 \%$ de mulheres, característica esta que é reflexo da constituição histórica da profissão ${ }^{22}$.

Em relação ao tempo de formação profissional, foi observado que dois entrevistados possuem entre 6 a 11 anos, sete participantes têm de 1 a 5 anos de formação e apenas um é formado há mais de 15 anos. No que diz respeito ao grau de especialização dos técnicos em enfermagem, todos eles possuem, no mínimo, uma especialização técnica, sendo a área de urgência e emergência prevalente, relatada por 4 profissionais. Com relação aos enfermeiros, apenas um deles não possui curso de pósgraduação, 2 deles apresentam especialização em urgência e emergência e 1 deles em auditoria, educação em saúde e docência na área da saúde. Estes resultados mostram a tendência da busca constante de atualização profissional, condizendo com a necessidade de qualificação da assistência oferecida à população, principalmente com o desenvolvimento de conhecimento teórico e prático. ${ }^{23}$

Entre os seis técnicos de enfermagem, quatro relataram que no curso técnico tiveram algum conhecimento referente a esta informação, porém, nada expressivo, algo muito superficial. Com relação aos enfermeiros, todos mencionaram possuir algum entendimento sobre o assunto, proveniente da graduação, porém, também destacaram que a abordagem sobre o tema foi realizada de forma ampla, sem especificações. Ressalta-se que nenhum dos profissionais entrevistados comentou ter recebido uma capacitação referente ao conteúdo, atentando quanto ao despreparo por parte dos profissionais no que diz respeito ao adequado manejo da dor. A capacitação das equipes de enfermagem são previstas pelas legislações vigentes de órgãos próprios de fiscalização da enfermagem, e sobretudo, constituem-se como uma necessidade frente às demandas de trabalho contemporânea, sendo de responsabilidade da própria instituição de saúde. 23 


\section{A dor como quinto sinal vital}

Quanto ao reconhecimento da dor como quinto sinal vital, os participantes expressaram diversos sentimentos. O participante PE 2 por exemplo, aponta como indicativo de dor a alteração de sinais orgânicos, conforme evidenciamos no trecho a seguir: "Muitas vezes a dor altera os outros sinais já reconhecidos anteriormente, por exemplo, pressão arterial, frequência cardíaca, frequência respiratória [...]. O mesmo participante ao finalizar sua colocação expõem que que por este motivo a dor deve ser considerada um sinal vital, visto a seguir, "Eu acho que a dor é um conjunto com os outros sinais".

O relato acima aproxima-se de estudos que demonstram que quando um sinal vital é alterado, esta situação é compensada por mudanças em outro sinal vital para manutenção da homeostasia ${ }^{23}$. Neste contexto, Padilha, Kleinpaul e Petry ${ }^{24}$ destacam que por meio desta interação, a presença de dor desencadeará alterações na atividade cardíaca, e, consequentemente na pressão arterial, frequência cardíaca e frequência respiratória. Desta forma, a inclusão da avaliação da dor juntamente com os outros sinais vitais garantirá o acesso às intervenções para o adequado manejo da sensação álgica, promovendo o seu alívio e controle dos demais parâmetros vitais.

Outro fator que merece destaque é a valorização da mensuração da dor por parte da equipe, os participantes referem basear-se nas condutas assistenciais e principalmente o prognóstico a partir da avaliação, conforme PE 8 refere no trecho:

"A dor nos dá sinais do que pode estar acontecendo com aquele paciente, por exemplo, caso a pessoa chega ao pronto atendimento referindo dor abdominal no lado direito, o profissional pode começar a investigar algumas possibilidades do por que daquela dor, como uma apendicite, por exemplo [...]."

O mesmo participante sinaliza a importância que ela possui até mesmo no dimensionamento dos diagnósticos, conforme o trecho: "Ela nos dá indícios do que pode estar acontecendo com aquele paciente [...]". E reforça ainda, o mesmo achado de PE 2 sobre a influência do sentimento de dor perante os demais sinais, conforme a frase a seguir: "Além disso, ela pode alterar os outros sinais vitais, como $P A$, frequência cardíaca e frequência respiratória".

É perceptível através das falas supracitadas que os profissionais consideram a avaliação da dor como uma ferramenta que traz subsídios na identificação do diagnóstico clínico dos pacientes. Sob este panorama, Araujo e Romero ${ }^{9}$, apontam que a avaliação da sintomatologia dolorosa é fundamental para se compreender a sua origem, intensidade e subsequentemente implementar medidas analgésicas. Sendo assim, é essencial para a equipe de enfermagem saber avaliar a dor para o manejo adequado e prestação dos cuidados necessários.

Outro fator importante sobre a dor enquanto sinal vital elencado pelos participantes é o agravo que pode ocorrer, principalmente na qualidade de vida dos indivíduos, PE 5 por exemplo cita a questão dos idosos, conforme o trecho: "A dor pode repercutir de várias formas na qualidade de vida dos idosos". O mesmo participante ainda reforça a sua afirmativa, oferecendo exemplos concretos verificados na prática, conforme o trecho: "Ela pode causar isolamento social, diminuição da autoestima, inatividade, entre tantos outros problemas, ela causa um sofrimento tanto físico quanto psíquico".

Concernente a isso, Monfrim e colaboradores $^{8}$ afirmam que o tratamento da dor não deve somente se concentrar nas suas consequências e sim, ir à busca da sua causa, atentando-se aos aspectos culturais, afetivos, emocionais, educacionais e ambientais do indivíduo. Todavia, alguns fatores como a falta de instrumentos aceitos internacionalmente nas instituições para a classificação da dor e a escassez de profissionais capacitados contribuem para um quadro negativo neste processo, fazendo-se necessário o aprimoramento das técnicas investigativas da dor e o aperfeiçoamento dos profissionais de saúde ${ }^{25}$.

\section{Avaliação da dor no contexto de pessoas idosas}

Quanto a avaliação da dor no contexto de indivíduos idosos, os participantes indicaram realizá-la na sua rotina de trabalho, PE 3 relata aplicá-la desde a primeira verificação dos sinais vitais, conforme o trecho: "Já na primeira avaliação dos sinais vitais eu avalio a dor do paciente". PE 3 ainda demonstra conhecimento e prática na avaliação ao exemplificar uma situação de aplicação das escalas, conforme a frase a seguir: "Caso a pessoa consiga se comunicar, então eu costumo pedir de forma indireta de 1 a 10 qual a dor dela".

Sob o mesmo limiar, o participante PE 7 
revela que realiza a avaliação da dor, no trecho "Eu sempre avalio". E concomitante ao participante anterior, PE 7 exemplifica a utilização de escalas de avaliação no cotidiano de sua assistência, como visto a seguir: "No momento em que são verificados os outros sinais vitais, você conversa com o paciente, pergunta a ele como está e, em alguns casos, mas não todos, eu aplico a escala de 0 a 10 de forma indireta".

Observa-se que a falta de um instrumento de avaliação da dor padronizado pela instituição dificulta a rotina de serviço dos profissionais e, consequentemente, reflete no cuidado prestado. Além disso, constatou-se que a maioria dos profissionais não avaliam a dor conforme recomendado, ou seja, não fazem avaliação de local, intensidade, início, duração, frequência, qualidade sensitiva, fatores que agravam e atenuam a dor, impacto gerado, bem como de seu padrão evolutivo. Neste contexto, Fontes e Jaques $^{19}$, discorrem que a avaliação da dor gera mudanças em toda equipe multidisciplinar, assim como, na própria organização de saúde, exigindo a elaboração de protocolos de avaliação e manejo da dor, como também na educação e treinamento contínuo para modificar condutas e práticas difundidas entre os profissionais.

Sobre o mesmo questionamento PE 1 declara ser objetivo e infere que em sua prática não utiliza escalas de avaliação em específico, conforme o seu relato a seguir: "Geralmente eu só pergunto se o paciente tá sentindo ou não dor, mas nada que seja avaliado mais especificadamente".

Nesta perspectiva, percebe-se que os profissionais, na maioria das vezes, apesar de reconhecerem a importância de avaliar a dor e realizar os registros de forma sistemática, não realizam estas práticas em suas rotinas. Infere-se que este fato esteja atrelado à formação acadêmica, visto que ainda existem lacunas no conhecimento e na prática assistencial associadas a esta temática. No entanto, acreditase que, se houver maior investimento na capacitação e sensibilização dos profissionais, haverá possibilidade de desenvolver um trabalho eficaz no cuidado integral à população idosa.

Em outro diálogo PE 9 relata utilizar a avaliação da dor somente em casos críticos, e nestas situações o profissional realiza um aprofundamento na coleta de informações secundárias, conforme o trecho: "Eu apenas avalio se a pessoa me relatar que está sentindo muita dor, então eu questiono quando começou a dor, se fez uso de alguma medicação, se essa dor é localizada, difusa e se irradia para algum membro ou outro local".
Conforme Andrade, Pereira e Sousa ${ }^{7}$, o processo de avaliação da dor é amplo e envolve um espectro de informações, como a data de início, localização, intensidade, interferência nas atividades diárias, entre outros. Além disso, para que o diagnóstico de dor no idoso seja preciso é necessário que a avaliação seja feita de forma exaustiva, com um exame físico minucioso, considerando a avaliação do estado funcional, psíquico e social, não se restringindo apenas no auto-relato do idoso.

Em contraponto aos achados anteriores, alguns profissionais relataram não utilizar a avaliação da dor em suas rotinas. PE 4 por exemplo, afirma que não a avalia pois não verifica esta prática como rotina no setor, conforme a frase: "Normalmente não, pois não é rotina aqui do $P A$ ". Buscando fundamentar a indicação, o mesmo participante relata que sempre segue a rotina da instituição, intuindo que a avaliação da dor não encontra-se nela, conforme o trecho: "Então é seguida sempre a rotina da instituição".

$\mathrm{O}$ grande desafio do combate à dor inicia na deficiência de sua avaliação. Apesar de algumas iniciativas a nível nacional demonstrarem preocupação em instituir a dor como quinto sinal vital nas instituições ${ }^{8}$, observa-se passividade dos profissionais de saúde no convívio cotidiano relacionado a este tema. Em alusão ao exposto, Christoffel et al. ${ }^{26}$ apontam que a implantação da avaliação da dor na prática clínica é uma tarefa árdua e que envolve vários aspectos individuais e organizacionais. Entretanto, as práticas devem ser baseadas em evidências e não simplesmente em rotina, tradição ou vivências individuais de profissionais envolvidos na assistência aos idosos.

Em uma das falas de PE 5 é verificado que em sua prática a dor não é avaliada por ser considerada uma atribuição de outro profissional, conforme a fala: "Na verdade não, pois quem faz a triagem do paciente é o enfermeiro, só nos casos em que o paciente relata que está sentindo dor, mas nada que seja mensurado".

Em menção a fala anterior, Silva e colaboradores $^{27}$ dissertam que em pacientes geriátricos, a dor pode vir acompanhada de peculiaridades como o declínio funcional dos órgãos, a concomitância de diversas morbidades e o efeito cumulativo da progressão de doenças crônicas dolorosas. Quanto este aspecto, Tamborelli et al. ${ }^{28}$ evidenciam que a abordagem multidisciplinar é de suma importância à esses pacientes devido a sua complexidade e, ratificam que nenhuma profissão isolada tem a capacidade 
de realizar a totalidade das ações demandadas no que se refere ao tratamento da dor, tornando - trabalho coletivo uma estratégia para redesenhar os processos laborais e promover a qualidade dos serviços.

Outro fator que merece destaque no contexto e que aparece como motivo da não utilização de escalas de avaliação da dor é a necessidade de capacitação sobre o assunto. $\mathrm{Na}$ fala de PE 6 percebe-se claramente que a avaliação é realizada, no entanto a contrapartida da instituição em capacitar os profissionais para tal atividade não está ocorrendo, conforme o trecho:

"Como na instituição não temos disponíveis as escalas e não tivemos nenhuma capacitação sobre o assunto, eu apenas questiono o paciente de 0 a 10 qual a dor que ele está sentindo naquele momento, se após um determinado tempo percebo que a dor não cessou, eu repasso para o enfermeiro ou médico, mas eles também não cobram da gente qual o grau da dor."

Esses dados chamam a atenção para a questão da falta de preparo, de atualização técnica e até mesmo de interesse dos profissionais de enfermagem, o que pode significar uma grave ruptura da responsabilidade ética de cada um $^{29}$. Nesse sentido, Silva, Pimenta e $\mathrm{Cruz}^{30}$ ressaltam que a atualização da equipe deve ser contínua, a fim de garantir uma assistência humanizada e de qualidade. Assim, infere-se que a educação continuada, promovida por meio de treinamentos e capacitações, seja o alicerce para a inserção de conhecimentos novos ou pouco elencados na prática assistencial de enfermagem.

Verifica-se ainda que alguns profissionais não possuem a proatividade em utilizar a avaliação, pois mesmo sabendo de sua necessidade, estão aguardando uma cobrança por parte da instituição, conforme o trecho: "Caso fosse implantada a avaliação da dor eu aceitaria e iria adequar à minha rotina, pois se é algo que será cobrado pelo nosso chefe, teremos que nos adaptar a essa regra" (PE1).

Observa-se por meio da fala anterior a necessidade de um acompanhamento contínuo e uma observação sistemática do enfermeiro para com a equipe. Neste contexto, o afastamento deste profissional no processo avaliativo e de gestão da dor pode trazer dificuldades por parte dos técnicos e auxiliares de enfermagem. Além disso, Oliveira et al. ${ }^{31}$ evidenciam que o enfermeiro têm o dever legal de exercer liderança diante dos diferentes fenômenos vivenciados por seus usuários.

\section{Conhecimento dos profissionais sobre metodologias de avaliação da intensidade da dor}

Sobre o conhecimento dos profissionais sobre metodologias de avaliação, verifica-se que em sua maioria tiveram contato durante a jornada acadêmica, conforme PE 10 indica na frase a seguir: "Eu lembro vagamente alguma coisa do curso técnico, não lembro a teoria em si, mas já era comentado [...] isso há 7 anos atrás". Demonstra ainda algum conhecimento sobre as escalas, indicando uma em específico que lembra, no seguinte trecho: "[...] lembro algumas coisas sobre a escala numérica, onde o paciente relata de 0 a 10 a intensidade da dor".

Sob o mesmo limiar, PE 3 também indica a escala numérica como lembrança de sua utilização nas práticas acadêmicas, conforme o trecho: "Sim, lembro na época de estágio que havia uma escala de 0 a 10, sendo que zero significa sem dor, cinco mais ou menos e 10 o máximo".

Embora não tenha sido amplamente referenciado, um número significativo dos profissionais entrevistados mencionaram conhecimento relacionado à escala numérica como instrumento de avaliação da dor e, ressaltam que muitas vezes questionam de forma não sistematizada qual o grau da dor do indivíduo em um parâmetro de 0 a 10. Em relação à escala numérica, estudos realizados por Andrade, Pereira e Sousa ${ }^{7}$, mostraram que esta escala mostra-se fidedigna na mensuração da experiência dolorosa em idosos, entretanto, alguns usuários apresentam dificuldade em utilizá-la por falta de habilidade cognitiva ou necessidade de domínio das propriedades aritméticas.

No diálogo realizado com o participante PE 7, é levantada novamente a questão dos idosos e trabalhada outras metodologias de avaliação da dor, mais subjetivas e integrantes, conforme a fala: "Em alguns casos, alguns idosos relatam que não estão com dor, então você observa pelas expressões faciais ou pela alteração dos outros sinais vitais que existe dor".

Alguns indivíduos não desejam que a equipe de enfermagem perceba a sua dor física, todavia, a negação do desconforto também é uma percepção que a enfermagem deve ter em relação ao paciente que sente dor. Concernente a estas assertivas, Padilha, Kleinpaul e Petry ${ }^{24}$ evidenciam que o olhar clínico e a educação 
continuada podem auxiliar os profissionais a identificar a dor do indivíduo, por meio da análise dos sinais que apresentam e dos comportamentos e atitudes que expressam. Algumas dessas expressões conforme Andrade, Pereira e Sousa ${ }^{7}$ podem ser verificadas por meio do isolamento social, fisionomias faciais (careta e arqueamento da sobrancelha), postura antálgica, vocalização e agitação.

Em contrapartida, PE 2 introduz a questão do tempo reduzido para avaliação da dor em sua rotina, induzindo que solicita verbalmente se o indivíduo possui dor ou não, em meio as demais questões, não aprofundando o questionamento e investigação, conforme o trecho:

"Pela questão da falta de tempo, quando eu converso com o paciente faço aquelas perguntas básicas, fez xixi, fez cocô, tá com dor, é automático, porém, muitas vezes o idoso não consegue expressar qual a dor dele, como no caso de um paciente com alzheimer e têm familiares que deixam eles sozinhos, não sabem nem quais medicamentos eles tomam, não convivem com eles."

Pode-se mencionar que há diversas dificuldades para a equipe de enfermagem em interpretar a dor do paciente e evidencia-se que o estresse e o cansaço fazem parte da rotina hospitalar. Em consonância, Peres e Ciampone ${ }^{32}$ apontam que a classe de enfermagem constantemente se submete a jornadas de trabalho exaustivas, o que gera desgaste e fadiga, entretanto, o manejo adequado da dor não pode ficar comprometido por questões trabalhistas, tornando-se necessário desenvolver conhecimento, habilidades e atitudes a fim de melhorar a assistência prestada.

Nessa mesma perspectiva, também pode-se constatar que em certos estágios da doença o paciente pode ser incapaz de participar ativamente nas medidas de alívio da sensação álgica, devido as alterações de habilidades cognitivas ou sensoriais que interferem na comunicação e, consequentemente na avaliação e mensuração da dor. Nessas circunstâncias, é necessário que o profissional de enfermagem esteja atento às expressões faciais e corporais que possam indicar que o indivíduo está com dor. Além disso, Araujo e Romero ${ }^{9}$ elencam que o envolvimento da família e sua participação no cuidado são fundamentais para que o profissional possa integrar os conhecimentos que já têm com os relatos coletados.

\section{Impactos do manejo clínico da dor}

Mesmo com todas as dificuldades na utilização de escalas e na sua realização prática, os indivíduos demonstram aceitação sobre o uso da avaliação em sua rotina. Neste sentido, PE 8 indica em sua fala a importância conferida no contexto de trabalho, verificado no trecho a seguir: "Acredito que seja muito importante avaliar, mensurar a dor no paciente, principalmente para nós que trabalhamos no Pronto Atendimento, que é a porta de entrada hospitalar, onde será planejada toda a assistência que será prestada".

Outra questão importante que aparece na fala do participante é a correta avaliação para uma tomada de decisão eficaz, já que o planejamento assistencial parte dos achados realizados na avaliação do indivíduo, conforme o trecho: "Nesse sentido, a avaliação do quinto sinal vital pode auxiliar o profissional na tomada de decisões e no acompanhamento da evolução da intensidade da dor".

É importante que a equipe de enfermagem esteja atenta às queixas subjetivas de cada indivíduo, de modo a intervir no processo sintomático da dor, possibilitando o seu alívio e conforto. Sendo assim, a medida que se mensura a dor como um sinal vital têm-se parâmetros para estabelecer um plano de cuidados, tornando-se fundamental a avaliação e registros dos dados de maneira sistemática.

Neste mesmo limiar, PE 3 indica que a realização da avaliação da dor torna-se importante por qualificar o atendimento, no entanto se for realizada com pouco tempo não traz benefícios para o planejamento do cuidado, conforme a fala:

"A utilização da avaliação da dor no setor consome mais tempo do profissional, pois uma coisa é só pedir se está ou não com dor, outra é você realizar uma avaliação minuciosa, questionando sobre o local, quando começou essa dor, quais fatores contribuem para melhora ou piora dessa sensação, porém, é visível que a qualidade no atendimento aumenta."

Em conformidade ao relato acima, Ribeiro et al. ${ }^{33}$ predizem que na ausência da analgesia, as consequências neurológicas, circulatórias, respiratórias ou metabólicas da dor podem ser prejudicadas, podendo agravar um quadro clínico já comprometido. Isso mostra que a qualidade da assistência ao idoso com dor está diretamente relacionada a uma adequada avaliação do 
processo álgico. Assim, na identificação da dor considera-se sua multidimensionalidade, sendo necessário abordar os aspectos emocionais e sensoriais que a permeiam.

O participante PE 4 levanta uma observação mais reflexiva sobre a prática assistencial e a utilização da avaliação da dor, inferindo sobre a qualificação da assistência e os princípios que regem a ética profissional, conforme o trecho:

"A dor sendo avaliada poderá mostrar ao profissional outra forma de olhar o paciente, de dar uma atenção a mais para ele, pensando em outras alternativas de cuidado, não apenas naquela centrada no tratamento, na cura da doença, e sim um cuidado integral, olhando para aquela pessoa como um todo."

No mesmo ponto de vista PE 10 relata a utilização da avaliação da dor em consonância ao atendimento humanizado, de acordo com as práticas contemporâneas de qualificação assistencial dos cuidados de enfermagem, conforme o trecho verificado a seguir:

"Vejo a utilização da avaliação da dor como uma forma de humanizar $o$ atendimento, onde deixamos de observar o paciente com um olhar técnico, fragmentado e nos voltamos para ele, para o que ele está nos relatando e sentido, tornando-o protagonista nesse cuidado."

Por meio dos relatos anteriores, pode-se observar que os profissionais compreendem que a avaliação da dor possibilita um melhor planejamento da assistência de enfermagem, bem como, viabiliza um cuidado integral e individualizado para o indivíduo com dor, tornando o atendimento mais humanizado e atento às necessidades. Neste panorama, Saça e colaboradores $^{25}$ enfatizam que a avaliação, controle e alívio da dor além de constituírem um aspecto humanitário, também são direitos do usuário e contribuem para a manutenção das funções fisiológicas básicas e evitam efeitos colaterais resultante do processo álgico.

Outros benefícios da avaliação da dor é levantado por PE 6 que em sua fala também retoma as questões de humanização e planejamento da assistência por meio de uma avaliação criteriosa do contexto, conforme o trecho:

"Por meio da avaliação da dor eu acredito que seja possível determinar se uma terapêutica está agindo positivamente para aquele paciente, além disso, o correto manejo da dor também favorece na recuperação, evita efeitos colaterais associados ao tratamento e diminui o tempo de internação daquele indivíduo."

Concernente a isso, Bueno, Benedet e Salum $^{34}$ mencionam que a adequada avaliação e realização do registro pelos profissionais é requisito essencial para o controle da dor, desta forma, será possível acompanhar a evolução do usuário e realizar os ajustes necessários na terapêutica, fomentando na redução do sofrimento, maior satisfação do cliente e redução de custos adicionais relacionados a possíveis complicações. Ademais, uma adequada avaliação da dor também possibilita identificar se os riscos de um tratamento superam os danos causados pelo problema clínico, bem como permite escolher a melhor e mais segura conduta terapêutica ${ }^{28}$.

\section{Conclusões}

A dor retrata-se como um fenômeno subjetivo e individual, correlacionada a fatores sociais, culturais e emocionais. Por meio dos resultados desse estudo, foi possível perceber que a dor e seu controle, ainda, se colocam como desafio aos profissionais de saúde, sendo fundamental inserir esses temas no curso de formação profissional, além de investir na educação continuada a fim de esclarecer dúvidas e rever conceitos errôneos referentes à dor.

Constatou-se que apesar da maioria dos profissionais considerar importante avaliar e mensurar a dor, todos eles realizam este processo de forma não sistematizada e possuem saberes incipientes quanto as novas tecnologias utilizadas para o manejo da sensação álgica em idosos. Acredita-se que por meio da instrumentalização do conhecimento sobre a dor e o uso de escalas para mensurá-la, esse processo tornar-se-ia mais objetivo e científico, não sendo verificado apenas por meio da observação empírica.

Algumas barreiras que impedem o manejo adequado da dor são notórias. Dentre elas, destacam-se a dificuldade da equipe em interpretar a dor em pacientes que apresentam alterações das habilidades cognitivas e a sobrecarga de trabalho dos profissionais de enfermagem. Estes achados evidenciam a necessidade de reorganizar a assistência de enfermagem oferecida aos idosos com dor que procuram atendimento hospitalar, apontando o manejo da dor como ponto fundamental para a 
humanização da assistência e qualidade do atendimento.

\section{Referências}

1. Ciena AP, Gatto R, Pacini VC, Picanço VV, Magno IMN, Loth EA. Influência da intensidade da dor sobre as respostas nas escalas unidimensionais de mensuração da dor em uma população de idosos e de adultos jovens. Semina: Ciências Biológicas e da Saúde, Londrina, 2008; 29 (2): 201-12.

2. Queiróz DTG, Carvalho MA de, Carvalho GDA de, Santos SR dos, Moreira ADS, Silveira MFA. Dor - 50 sinal vital: conhecimento de enfermeiros. Revista de Enfermagem, Recife, 2015; 9 (4): 7186- 192.

3. Silva JA, Ribeiro Filho NP. A dor como um problema psicofísico. Revista Dor, São Paulo, 2011; 12 (2): 138-51.

4. Sallum AMC, Garcia DM, Sanches M. Dor aguda e crônica: revisão narrativa da literatura. Acta paul. enferm., São Paulo, 2012; 25(1): 150-4. 5. Giro A, Paúl C. Envelhecimento Sensorial, Declínio Cognitivo e Qualidade de Vida no Idoso com Demência. Actas de Gerontologia, 2013; 1 (1): 1-10.

6. Rios JCS, Leite TKM, Pereira MM, Sousa FC, Safons MP. Efeitos de um programa educacional de autocuidado de coluna em idosos com dor lombar crônica: um estudo quaseexperimental. Motricidade, 2015; 11 (1): 53-63.

7. Andrade FA, Pereira LV, Sousa FAEF. Mensuração da dor no idoso: uma revisão. Rev. Latino-Am. Enfermagem, Ribeirão Preto, 2006; 14 (2): 271-6.

8. Monfrim XM, Saraiva LA, Moraes CL, Viegas AC. Escala de avaliação da dor: percepção dos enfermeiros em uma Unidade de Terapia Intensiva neonatal. Rev Enferm UFSM, 2015; 5(1): 12-22.

9. Araujo LC, Romero B. Dor: avaliação do quinto sinal vital. Uma reflexão teórica. Revista Dor,São Paulo, 2015; 16 (4):291-6.

10. Nascimento JCC, Silva LCS. Avaliação da dor em pacientes sob cuidados em Unidades de Terapia Intensiva: uma revisão de literatura. Revista Movimenta, 2014; 7(2): 711-20.

11. Thé KB, Gazoni FM, Cherpak GL,Lorenzet IC, Santos LA dos, Nardes EM, et al. Avaliação de dor em idosos dementados: validação da versão brasileira da escala PACSLAC. Revista Einstein, São Paulo, 2016; 14(2): 152-57.

12. Cunha LL, Mayrink WC. Influência da dor crônica na qualidade de vida em idosos. Rev. Dor, São Paulo, 2011; 12(2): 120-24.
13. Pedroso RA, Celich KLS. Dor: quinto sinal vital, um desafio para o cuidar em enfermagem. Texto \& Contexto Enferm., 2006; 15(2): 270-6.

14. Fortunato JGS, Furtado MS, Hirabae LFA, Oliveira JA. Escalas de dor no paciente crítico: uma revisão integrativa, Revista Hupe, Rio de Janeiro, 2013; 12(3): 110-17.

15. Leão $E$, Chave LD. Dor: 5o sinal vital: reflexões e intervenções de enfermagem. Curitiba, Editora: Maio; 2004.

16. Sousa FAEF. Dor: o quinto sinal vital. Rev Latino-am Enfermagem, Ribeirão Preto, 2002; 10 (3): 446-7.

17. Martinez JE, Grassi DC, Marques LG. Análise da aplicabilidade de três instrumentos de avaliação de dor em distintas unidades de atendimento: ambulatório, enfermaria e urgência. Rev. Bras. Reumatol., 2011; 51 (4): 304-08.

18. Sousa FF, Pereira LV, Cardoso R, Hortense P. Escala Multidimensional de Avaliação de Dor (EMADOR). Rev. Latino-Am. Enfermagem., 2010; 18 (1): 3-10.

19. Fontes $K B$, Jaques $A E$. O papel da enfermagem frente ao monitoramento da dor como 5으 sinal vital. Cienc Cuid Saude, 2007; 6 (1): 481-87.

20. Heinen $A C$, Goulart $C L$, Sudbrack $A C$, Fleig MTC, Silva ALG. Avaliação da dor como quinto sinal vital: uma escolha profissional de intervenção fisioterapêutica. Revista Pesquisa em Fisioterapia, 2016; 6(4): 379-86.

21. Bardin L. Análise de Conteúdo. São Paulo: Edições, 70; 2011.

22. Conselho Federal de Enfermagem (COFEN). Pesquisa inédita traça perfil da enfermagem. In: Conselho Federal de Enfermagem. Brasília; 2015. Disponível em: < http: // http://www.cofen.gov.br >. Acesso em: 16 de outubro de 2017.

23. Potter P, Perry AG. Fundamentos de enfermagem. 8 ed. Rio de Janeiro: Elsivier; 2013. 24. Padilha DB, Kleinpaul WV, Petry AR. Possibilidades e desafios enfrentados pelo profissional de enfermagem no atendimento ao paciente com sintomatologia dolorosa. Revista Eletrônica de Enfermagem do Vale do Paraíba, 2013; 1(5): 125-41.

25. Saça CS, Carmo FA do, Arbuleia JPS, Souza RCX de, Alves SA, Rosa BA. A dor como 5은 sinal vital: atuação da equipe de enfermagem no hospital privado com gestão do Sistema Único de Saúde (SUS). J health sci inst, 2010; 28(1): 35-41. 26. Christoffel MM, Castral TC, Daré MF, Montanholi LL, Gomes ALM, Scochi CGS. Atitudes dos profissionais de saúde na avaliação e 
tratamento da dor neonatal. Esc. Anna Nery, Rio de Janeiro, 2017; 21(1).

27. Silva JPG da, Costa KNFM, Silva GRF da, Oliveira SHS, Almeida PC de, Fernandes MGM. Consulta de enfermagem a idosos: instrumentos da comunicação e papéis da enfermagem segundo Peplau. Esc. Anna Nery, 2015; 19 (1): 154-61.

28. Tamborelli V, Costa AF da, Pereira VV, Torturella M. O papel da enfermagem e da fisioterapia na dor em pacientes geriátricos terminais. Geriatria \& Gerontologia, 2010; 4(3): 146-53.

29. Blasi DG, Candido LK, Tacla MTGM, Ferrari RAP. Avaliação e manejo da dor na criança: percepção da equipe de Enfermagem. Semina: Ciências Biológicas e da Saúde, Londrina, 2015; 36 (1): 301-10.

30. Silva MAS, Pimenta CAM, Cruz DALM da. Treinamento e avaliação sistematizada da dor: impacto no controle da dor do pós-operatório de cirurgia cardíaca. Rev Esc Enferm USP, 2013; 47 (1): 84-92.

31. Oliveira PEP, Pereira LV, Santos NR, Souza LAF. A enfermagem no manejo da dor em unidades de atendimento de urgência e emergência. Revista Eletrônica de Enfermagem, Goiânia, 2016; 18 (1).

32. Peres AM, Ciampone MHT. Gerência e competências gerais do enfermeiro. Texto \& Contexto Enferm., 2006; 15 (3): 492-9.

33. Ribeiro NCA, Barreto SCC, Hora EC, Sousa RMC de. O enfermeiro no cuidado à vítima de trauma com dor: o quinto sinal vital. Rev. esc. enferm. USP, São Paulo, 2011; 45 (1): 146-52.

34. Bueno LX, Benedet AS, Salum NC. Vivência dos profissionais de enfermagem frente a dor: uma estratégia de humanização do cuidado. Revista Eletrônica Gestão \& Saúde, 2012; 3 (3): 999-1012.

\section{Endereço para Correspondência}

Universidade do Vale do Taquari - UNIVATES

Av. Avelino Talini, 171 - Universitário, Lajeado - RS,

CEP.: 95914-014

e-mail: Ipissaia@universo.univates.br

Recebido em 07/01/2018

Aprovado em 02/05/2018

Publicado 30/06/2018 